\title{
Screening a set of tomato parental lines and their hybrids for resistance to early blight (Alternaria solani) by detached leaf method
}

\author{
Bharathkumar M. V. ${ }^{1^{*}}$, Sadashiva A. T. ${ }^{2}$, Anjanappa M. ${ }^{3}$ and Amarananjundeshwara ${ }^{3}$ \\ ${ }^{1}$ Department of Vegetable Science, CCS Haryana Agricultural University, Hisar 125004 (Haryana), INDIA \\ ${ }^{2}$ Indian Institute of Horticultural Research, Bengaluru 560089 (Karnataka), INDIA \\ 3University of Horticultural Sciences, Bagalkot 587104 (Karnataka), INDIA \\ *Corresponding author E-mail: bharathkumarmv809@gmail.com
}

Received: September 25, 2016; Revised received: February 11, 2017; Accepted: June 28, 2017

\begin{abstract}
Nine parental lines and 18 hybrids derived by crossing them in Line $\times$ Tester fashion were screened against the early blight pathogen Alternaria solani along with a resistant, susceptible and a commercial check in the form of Arka Rakshak, IIHR2202 and Abhinava respectively. Parental lines and the resistant and susceptible checks were screened over two seasons and results obtained were almost similar with the line IIHR1816 exhibiting resistance with the disease severity of $25 \%$ in both the trials, while the line IIHR977 was found to be resistant in the first season with PDI of $25 \%$ and moderately resistant in the second season with the slightest increase in the disease severity up to $25.6 \%$. None of the hybrids were found to be resistant except, whereas about eight hybrids were found to be moderately resistant. IIHR2892 x IIHR2853 was found to be highly susceptible with severity of $68.75 \%$, which is on par with the susceptible check IIHR2202 $(70.50 \%)$. The results obtained from the detached leaf method of screening should be confirmed by the field or greenhouse screening methods before using them in further breeding programmes.
\end{abstract}

Keywords: Early blight, Alternaria solani, Artificial/Detached leaf, Screening, Tomato

\section{INTRODUCTION}

Tomato (Solanum lycopersicumL., $2 \mathrm{n}=24$ ) is one of the most remunerable and widely grown vegetables that ranks next to potato in the world acreage and first in area among the processing crops. Although, tomato does not rank high in nutritional value, by virtue of volume consumed, it contributes significantly to the dietary intake of vitamins $\mathrm{A}$ and $\mathrm{C}$, as well as essential minerals and other nutrients. Since tomato is a very good source of income to small and marginal farmers in India, it ranks third in area immediately after potato and onion crop and second in production immediately after the potato Crop (Anonymous, 2015). In India, the major biotic constraints in the cultivation and production of tomato are the occurrence of many insect pests. Diseases are the first concern to fresh market tomato and processing industries throughout the world since economic losses due to crop damage or disease control measures are significant. Tomato is susceptible to over 200 diseases (Lukyanenko, 1991) caused by pathogenic fungi (viz., Late blight, Early blight, Powdery mildew, wilts by Fusarium spsand Verticillium sps etc), bacteria (Bacterial wilt, spot, speck), viruses (TYLCV, TSWV, ToLCV, ToMV), or nematode (Root-knot nematode). Fungal diseases are major among the most destructive diseases of tomato under congenial environmental conditions. These diseases have the potential to drastically damage the tomato plant, render fruit unmarketable, reduce yield and cause significant economic losses. Early blight is the major disease symptom caused by the fungus Alternaria solani (Ellis \& Martin) Sorauer that belongs to Deuteromycotina (Fungi Imperfecti) in the class Hyphomycetes and order Hyphales (Agrios, 2005). The conidia of $A$. solaniare muriform and beaked (Ellis and Gibson, 1975). Under free moisture or near-saturated humidity at a wide range of temperatures $\left(8^{\circ}-32{ }^{\circ} \mathrm{C}\right)$, conidia germinate to produce one or more germ tubes. These subsequently penetrate the host epidermal cells directly by means of appressoria or they enter through stomata or wounds by hyphal growth. It affects all above ground parts of the tomato plant in three distinct phases depending on the symptoms as: collar rot in seedlings (stem lesions or cankers), leaf blight (commonly referred to as early blight) and fruit rot (sunken lesions at the stem end of the fruit). The leaf blight phase normally appears during the adult phase of the tomato plant, though it can also be seen at earlier stages. It first appears as dark, small and coalescing concentric lesions (target-like appearance), usually on lower older leaves and progresses upward as the plant reaches maturity (Rotem, 1994). The tissue surrounding the lesions turns yellow, senesces and the cells die through a non-host specific action of the pathogen, which produces toxic secondary metabolites such as alternaric acid and zinniol (Lawrence et al., 2000). The leaves eventually either 
dry up or fall off, leading to complete defoliation of the plant towards the end of the season (Barksdale and Stoner, 1977).

This disease, in severe cases can lead to complete defoliation inregions with heavy rainfall, high humidity, and fairly high temperatures $\left(24^{\circ}-29^{\circ} \mathrm{C}\right)$. Epidemics can also occur in semiarid climates where frequent and prolonged nightly dews occur (Rotemand Reichert, 1964) resulting in yield loss between 15 and 100 per cent (Sohi, 1984).It may cause considerable damage to the tomato crop in northern plains and peninsular regions of India and may act as a limiting factor for its successful cultivation in these regions (Lohith et al., 2011). To develop stable resistance in a variety, source of resistance would be of prime importance and hence, different methods are used to screen tomato germplasm from different sources against early blight that involves both field and artificial evaluation. Field evaluation have major drawbacks like long duration of test, uncontrollable environmental conditions necessary for infection, effect of whole plant physiology and the presence of other foliar pathogens (Pandey et al., 2003). An alternative method to obtain more precise and reliable disease reading is offered by detached leaf method that can overcome the whole plant physiology of disease resistance and also reduces the time, space and labour required to screen the genotypes. With the above facts and figures in mind, present work was designed and carried out during rabi of 2013-14 and summer of the year 2014 with the objective of knowing the reaction of various parental lines and their hybrids against early blight (Alternaria solani) of tomato (Solanum lycopersicum L.).

\section{MATERIALS AND METHODS}

Experimental materials comprised of nine parental lines of tomato, which were crossed in Line $\times$ Tester fashion to obtain eighteen hybrid derivatives. In the first season only nine parental lines were screened, whereas in the second season eighteen hybrids along with their parents and three check varieties (a resistant, susceptible and a commercial checks each) were screened adding up the sum to thetotal of 30 entries. Each entry was comprised of 40 plants in each replication, which were grown in an open field without any fungicidal spray in three replications.

Isolation of pathogen: The pathogen Alternaria solani was isolated at IIHR, Bengaluru from infected tomato leaves showing typical early blight symptoms. The infected sample under aseptic condition was used to obtain isolate by tissue segment method (Aneja, 2001) and the pathogenicity of the same isolate was proved by using a susceptible check. Virulent isolate of the pathogen was maintained in PDA slant for further use in course of investigation.

Experimental set-up: The detached leaf bioassay was conducted under laboratory conditions. For the study, leaflets were selected from open field grown plants without any fungicidal treatments were used for the purpose. For each entry 3 plants were randomly select- ed in each replication and the physiologically matured trifoliate leaflets (fourth leaf from tip of the plant) were collected for the experimentation. Moisture chamber was prepared by placing sterile moist blotting sheet in the Petri plate $(18 \mathrm{~cm}$ diameter; $2 \mathrm{~cm}$ deep with a lid). RH of about $90-95 \%$ was maintained by adding $15 \mathrm{ml}$ of double distilled water each day which favours the disease development. Sterile glass slides were placed to avoid direct contact of the leaflets with the moist surface of the blotting sheet and thereby avoiding the rotting of leaflets during the course of investigation. Each leaflet under investigation was placed in a separate Petri plates with above mentioned set up.

The pathogen Inoculum was multiplied on potato dextrose agar media. A circular mycelial disc of $5 \mathrm{~mm}$ diameter was taken from the growing edge of the seven days old colony. The leaves were pin pricked at the centre to facilitate the entry of pathogen and he disc was placed such that the mycelia should face the upper surface of leaf. Inoculation is done only on the middle leaf of the leaflet, whereas the other two leaves serves as a protective cover to maintain turgidity of the middle leaf during the process of screening. The inoculated leaflets were incubated in dark for $24 \mathrm{~h}$ at $\sim 22^{\circ} \mathrm{C}$, and then maintained under cool white fluorescent diurnal light with a 12 hours photoperiod. The development of lesion was observed each day and finally disease severity was recorded on seventh day based on the area covered by the pathogen on the inoculated leaf using 0-4 scale developed by Devananthan and Ramanujam (1995): $0=$ infection free or healthy; $1=1-25 \%$ leaf area blighted; $2=26-50 \%$ leaf area blighted; $3=51$ $75 \%$ leaf area blighted; 4=76-100\% leaf area blighted. The individual leaf ratings thus recorded were used to calculate the percentage disease index (PDI) using the formula:

PDI $=$ Sum of numerical ratings/Total number of leaves assessed $\times$ Maximum disease rating $\times 100$

Parental lines and hybrids were then grouped into five categories based on the PDI value (Mckinney, 1923) as: $<1 \%=$ immune; $1-10 \%=$ highly resistant; $10.1-25$ $\%=$ resistant; $25.1-40 \%=$ moderately resistant; 40.1-50 $\%=$ susceptible; $>50 \%=$ highly susceptible.

\section{RESULTS AND DISCUSSION}

Nine parental lines and their 18 hybrid derivatives were evaluated for early blight disease severity under laboratory conditions along with that of a resistant check (Arka Rakshak), a susceptible check (IIHR2202) and a commercial hybrid check (Abhinava) during 2014 at Indian institute of Horticulture Research, Bengaluru. The parental lines were initially been screened under the same set up during 2013-14 and were then crossed among themselves to produce eighteen hybrid derivatives. Lohith et al. (2011) screened about 52 tomato genotypes by using the similar method, but employing the droplet method of inoculation instead of mycelial disc. Similarly, Fooland et. al. (2000) also 
Bharathkumar M. V. et al. / J. Appl. \& Nat. Sci. 9 (3): 1305 -1309 (2017)

Table 1. Disease reaction of parents and their hybrids (in terms of Per cent Disease Index).

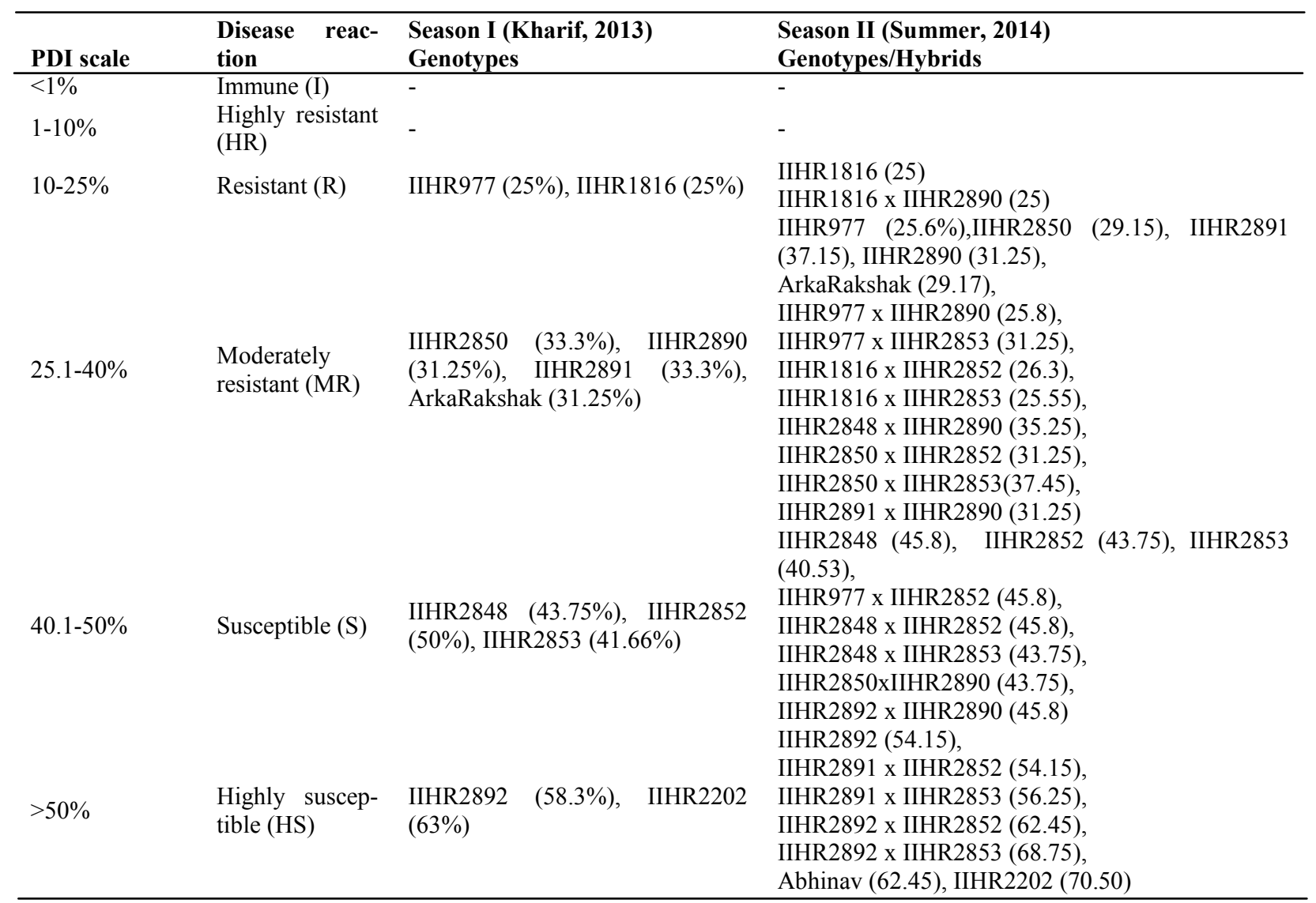

* Values in parentheses indicates the per cent disease index of respective entry

**I-Immune, HR-Highly Resistant, R-Resistant, MR-Moderately Resistant, S-Susceptible, HS-Highly susceptible

used droplet technique to screen 29 tomato genotypes for early blight to compare the efficacy of field, greenhouse and detached leaflet methods using. The performance and grouping of all the entries is presented in Table 1 and the reaction of some of them are provided in Fig. 1.

The screening results of the parental lines along with the checks clearly described the similar disease reaction over both the seasons, except that the line IIHR977 was found to be moderately resistant with PDI of 25.6during second season, which was in the first season found to be resistant with disease severity of $25 \%$. None of the parents were found to be immune or highly resistant to early blight, whereas IIHR1816 was found to be stably resistant over both the seasons. Three parents each were found to be moderately resistant [IIHR2850 (29.15\%), IIHR2891 (37.15\%), IIHR2890 (31.25\%)] and susceptible [IIHR2848 (45.8 $\%), \quad \operatorname{IIHR} 2852(43.75 \%), \operatorname{IIHR} 2853(40.53 \%)]$ in their reaction over both the experimental seasons, while the line IIHR2892 was reported to be highly susceptible with the disease severity of $58.3 \%$ and $54.15 \%$ in both the time period of experimentation. ArkaRakshak, the resistant check used was found to be moderately resistant over both the trials with the sever- ity of $31.25 \%$ and $29.17 \%$, whereas the susceptible check IIHR2202 was found to be highly susceptible with PDI of 63 and 70.5. Kumar and Srivastava (2013) conducted a field screening of 44 tomato genotypes against natural infection of early blight of tomato caused by Alternaria solani for two seasons at Varanasi, India and reported different disease reactions ranging from highly susceptible to highly resistant. Similarly, advanced lines of tomato were tested under natural infection of early blight at Mexico by Leyva-Mir et al. (2013) to reveal that line ' 60 ' and line ' 10 ' were tolerant with less area under the disease progress curve and least disease severity of $33 \%$ and $35 \%$, respectively. These cases thus suggest that, there may be variable disease reaction against Alternaria solani based on environmental conditions, genetic makeup of the cultivar and pathogen virulence.

None of the hybrid was found to be immune or highly resistant, but IIHR1816 x IIHR2890 was reported to be resistant with disease severity of $25 \%$. As much as eight hybrid combinations were observed to be moderately resistant to early blight with the disease severity ranging from $25.8 \%$ and $26.3 \%$ in IIHR977 x IIHR2890 and IIHR1816 x IIHR2852, respectively to 

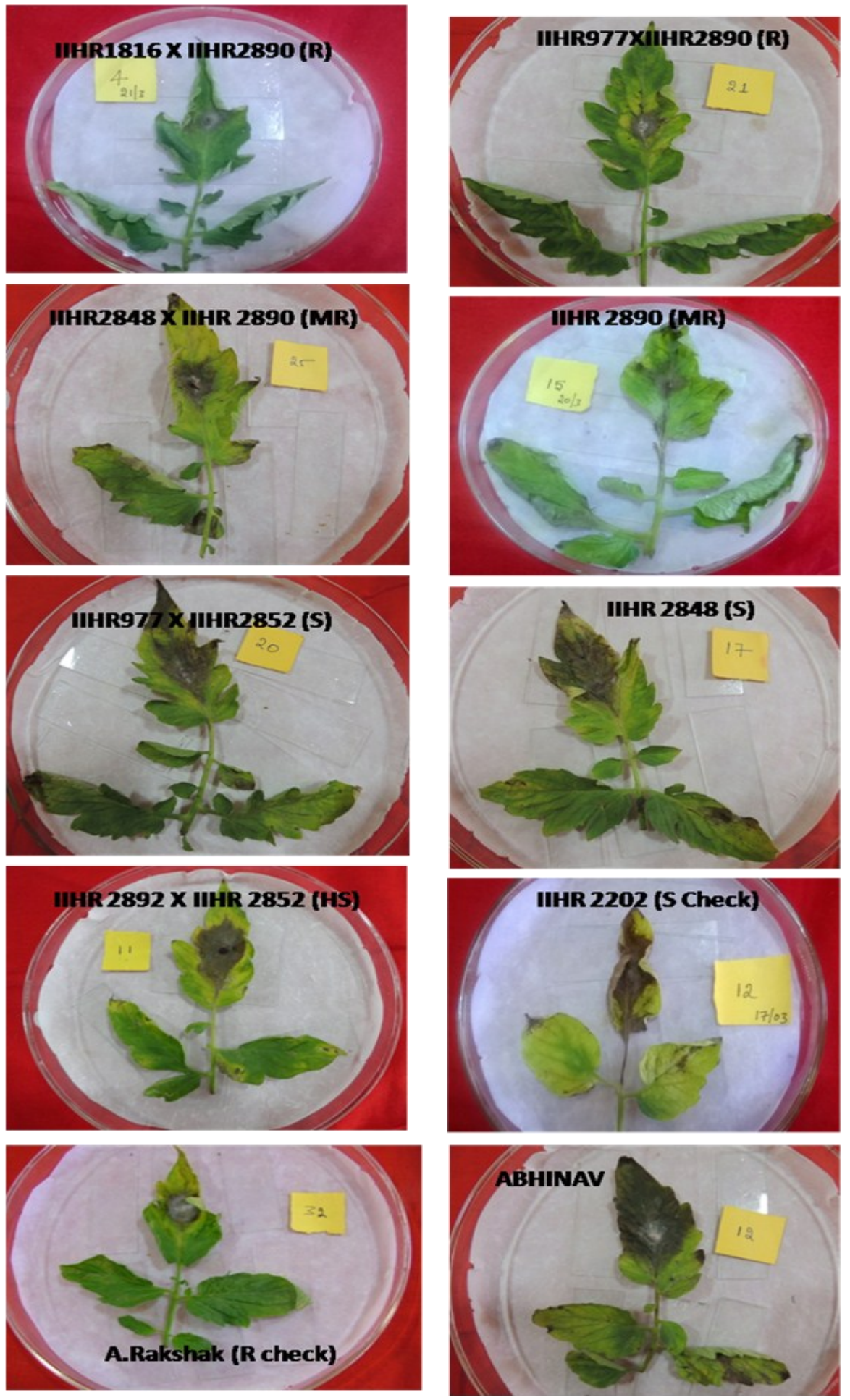

Fig. 1. Disease reaction of few parents, hybrids and check entries $(* R$-Resistant, MR-Moderately Resistant, S-Susceptible, HSHighly susceptible).

$37.45 \%$ in IIHR2850 x IIHR2853. Five hybrid combinations were susceptible to the early blight pathogen with the disease index ranging from $43.75 \%$ to $45.5 \%$ and four hybrids were highly susceptible with the hybrid IIHR2892 x IIHR2853 recording the highest disease severity of $68.75 \%$, which is on par with the susceptible check
IIHR2202 (70.50\%). In general, the hybrids derived from the parents IIHR1816, IIHR977 and IIHR2890 were observed to be resistant to moderately resistant claiming that the genetical factors from these parents would have contributed for the resistance in their hybrids.

Thirthamallappa and Lohithaswa (2000) reported that 
IIHR1816 was geneticallyresistant to early blight that may add up to the fact that the resistance shown by its hybrid derivative is genetical. The parental line IIHR1816 is nothing but NCEBR-1 (A.T. Sadashiva, pers. commun.) developed by Nash and Gardner (1988) that has genetical resistance against Alternaria solani, derived from the wild source Lycopersiconhirsutum L. (currently Solanum habrochaites S. Knapp \& D.M. Spooner). Detached leaf assay against powdery mildew of pea was performed by Singh et al. (2015), and it was found to be effective by excising the fifth leaf from the third node below the apex from 40 day old greenhouse grown pea plant that was placed on cotton sheets in petri dishes. Similarly, the method employed in this experiment is on the same principle and can be used effectively to screen tomato genotypes against early blight. But it is most essential to confirm the resistance expressed by these parental lines and their hybrids by field or greenhouse screening, since no better correlation was obtained among the results obtained by detached leaf screening with that of the whole plant screening for early blight of tomato (Fooland et al., 2000). Parental lines like IIHR1816, IIHR977 and IIHR2890 could be used in further screening and breeding experiments as a source of early blight resistance in tomato after thorough study of the same under different environment and screening techniques.

\section{Conclusion}

Results from the present experiment revealed that, parental lines IIHR1816 (25\%), IIHR977 (25.6\%), IIHR2850 (29.15\%), IIHR2891 (37.15\%), IIHR2890 $(31.25 \%)$ and some of their derived hybrids were found to be resistant or moderately resistant, and hence can be helpful in reducing the yield losses due to infection by Alternaria solani. Field and greenhouse screening of tomato for early blight pathogen may provide us with most reliable results, but they are not feasible practically when the population size under study is very large and time available is limited since they need considerable inputs in terms of land, labour and other resources. Using present methodology of detached leaf assay in petri plates may provide congenial environment for disease development and also saves the time and resources effectively, also confirmation of results by this method can be performed for selected entries by employing the other screening methods.

\section{REFERENCES}

Agrios, G. N. (2005). Plant pathology, 5th edn. Elsevier, London Ellis MB, Gibson IAS (1975) Alternaria solanino. 45 set 48. Commonwealth Mycological Institute, Kew, Surrey, UK.

Aneja, K. R. (2001). Experiments in microbiology, plant pathology, tissue culture and mushroom production technology (3rd Edition). New Age International (Pvt.) Ltd. Publishers, New Delhi. P. 568.

Anonymous (2015). Indian horticulture database, National horticulture board. Retrieved from www.nhb.gov.in.

Barksdale, T. H., Stoner, A. K. (1977). A study of the inheritance of tomato early blight resistance. Pl. Dis. Rep., ,61: 63-65

Devananthan, M. and Ramanujam, K. (1995). Evaluation of fungicides for the management of early blight of tomato caused by Alternaria solani. Madras Agricultural Journal, 82: 228-229

Ellis, M. B. and Gibson (1975).Alternaria solanino. 45 set 48. Commonwealth Mycological Institute, Kew, Surrey, UK.

Fooland, M. R., Ntahimperan, N., Christ, B. J. and Lin, G. Y. (2000). Comparision of field, greenhouse, and detached -leaflet evaluations of tomato germplasm for early blight resistance. Plant Dis., 34: 967-972

Kumar, S. and Srivastava, K. (2013). Screening of tomato genotypes against early blight (Alternaria solani) under field condition. The Bioscan, 8(1): 189-193

Lawrence, C. B., Singh, N. P., Qiu, J., Gardener, R. G. and Tuzun, S. (2000). Constitutive hydrolytic enzymes are associated with polygenic resistance of tomato to Alternaria solani and may function as elicitor release mechanism. Physiol. Mol. Plant Pathol., 57: 211-220

Leyva-Mir, S. G., González-Solano, C. M., Rodríguez-Pérez, J. E. and Montalvo-Hernández, D. (2013). Behavior of advanced lines of tomato (Solanum lycopersicum L.) to phyto-pathogens at Chapingo, Mexico. RevistaChapingo Serie Horticultura, 19(3): 301-313

Lohith, M. R., Reddy, K. C., Ramana, C. V., Rao, P. V., Reddy, K. R. and Reddy, D. L. (2011). Screening of tomato genotypes against early blight (Alternaria solani) by detached leaf method. Acta Hort., 914: 465-468

Lukyanenko, A. N. (1991). "Disease resistance in tomato," in Genetic Improvement of Tomato, G. Kalloo, Ed., vol. 14 of Monographs on Theoretical and Applied Genetics, Pp. 99-119

Mckinney, H. H., (1923). Influence of soil temperature and moisture on infection of wheat seedlings by Helminthosporiumsativium. Journal of Agricultural Research, 26: $195-217$

Nash, A. F. and Gardner, R. G. (1988). Tomato Early blight resistance in a breeding line derived from Lycopersiconhirsutum PI 126445. Plant Dis., 12: 206-209

Pandey, K. K., Pandey, P. K., Kallo, G. and Banerjee, M. K. (2003). Resistance to early blight of tomato with respect to various parameters of disease epidemics. J. Gen. Plant Pathol., 69: 364-371

Rotem, J. and Reichert, I., (1964). Dew - a principal moisture factor enabling early blight epidemics in a semiarid region of Israel. Plant Dis. Rep., 48:211-215

Rotem, J. (1994). Our knowledge of Alternaria pathogens and diseases. In: The Genus Alternaria: Biology, Epidemiology, and Pathogenicity, APS Press, St. Paul, Minn., Pp. 326

Singh, J., Dhall, R. K. and Aujla, I. S. (2015). Characterization of resistance response of garden pea (Pisumsativum L.) against powdery mildew (Erysiphepisi Dc) in subtropical plains of India. SABRAO Journal of Breeding and Genetics, 47(4): 384-393

Sohi, H. S. (1984). Present status of our knowledge of imperfect fungal diseases of selected vegetables in India and future needs. Indian J. Mycol. Pl. Pathol., 14: 1-34

Thirthamallappa and Lohithaswa, H. C. (2000). Genetics of resistance to early blight (Alternaria solani) in tomato (LycopersicumesculentumL.). Euphytica, 113: 187-193. 